\title{
Biological Behavior of the Gerbil Ventral Prostate in Three Phases of Postnatal Development
}

\author{
SILVANA GISELE PEGORIN DE CAMPOS, ${ }^{1}$ CRISTIANI ZANETONI, ${ }^{1}$ \\ REJANE MAIRA GÓES, ${ }^{2}$ AND SEBASTIÃO ROBERTO TABOGA ${ }^{2 *}$ \\ ${ }^{1}$ Department of Cell Biology, Institute of Biology, UNICAMP, São Paulo, Brazil \\ ${ }^{2}$ Laboratory of Microscopy and Microanalysis, Department of Biology, \\ IBILCE/UNESP, São Paulo, Brazil
}

\begin{abstract}
In this study, we characterized the gerbil's ventral prostate histology ultrastructurally and quantitatively throughout three phases of postnatal development (young, adult, and old) in order to comprehend its biological behavior and propensity to developing spontaneous lesions with aging. The gerbil prostate is composed of alveoli and ducts immersed in a stroma composed of smooth muscle, fibroblasts, collagen and elastic fibers and vessels. The prostate tissue components present morphological and quantitative aspects that vary according to age. Young animals have an immature gland with modest secretory activity. Synthetic activity remained stable in adult and old gerbil. However, prostatic morphology was altered in the aging, showing an increased epithelium and stromal fibrosis. The nuclei of the secretory cells increased with aging, whereas nucleoli presented few alterations during postnatal development. The epithelial proliferation and stromal remodeling noted in this study indicate that the gerbil prostate may respond to the androgen declines typical of senescence through epithelial proliferation and stromal remodeling. Anat Rec Part A, 288A:723-733, 2006. ๑ 2006 Wiley-Liss, Inc.
\end{abstract}

Key words: gerbil; ventral prostate; epithelium; stroma; proliferative lesions; aging

The prostate is a male accessory sex gland that, together with the seminal vesicle, produces the bulk of the seminal fluid. It is composed of two distinct compartments, the epithelial and the stromal or mesenquimal (Hayward et al., 1996). Prostatic morphogenesis is initiated in the fetal stage from the urogenital sinus and lasts until sexual maturity is fully obtained. The growth and development of the prostate are dependent on circulating androgens produced by the testes, and its homeostatic state during adult life is maintained by these steroid hormones, which act via stromal-epithelial interactions (Cunha et al., 1986; Marker et al., 2003). Thus, when the prostate attains adult size, a balance between cell proliferation and cell death is established so that no further growth occurs in the gland (Banerjee et al., 2000, 2001). However, during aging in man and several other species, including the dog and some strains of rodent, cellular hyperplasias may occur despite a decrease in the production of sex hormones such as testosterone, generating age-dependent prostatic hyperplasias (Bonkhoff and Rem- berger, 1998; Banerjee et al., 2001; Leav et al., 2001). These alterations may evolve into prostate cancer, a disease that affects men throughout the world, which takes the form of a lesion with heterogeneous behavior that is

The first two authors contributed equally to this work.

Grant sponsor: Brazilian National R\&D Council (CNPq); Grant sponsor: Coordenação de Aperfeiçoamento de Pessoal de Nível Superior (CAPES); Grant sponsor: São Paulo State Research Foundation (FAPESP).

*Correspondence to: Sebastião Roberto Taboga, Departamento de Biologia, IBILCE/UNESP, Rua Cristóvão Colombo, 2265, Jardim Nazareth, São José do Rio Preto, SP, 15054-000, Brazil. Fax: 55-17-32212390. E-mail: taboga@ibilce.unesp.br

Received 3 November 2005; Accepted 23 March 2006 DOI 10.1002/ar.a.20347

Published online 15 June 2006 in Wiley InterScience

(www.interscience.wiley.com). 
still poorly understood. For this reason, recent decades have witnessed a growth in interest in both the morphology and behavior of the prostate during its normal development and in different disorders that target this gland during senescence.

A number of animal models, particularly murines, have been used for prostate study. These studies have examined significant similarities and differences in the gross and microscopic anatomy between the rat, mouse, and human prostate and have analyzed the potential of these models to recapitulate human prostatic disease (Huss et al., 2001; Roy-Burman, et al., 2004). The rodent prostate complex is composed of four distinct paired lobes, the ventral, lateral, dorsal, and anterior, each of which serves a particular function in relation to histology and secretory protein production (Sugimura et al., 1986). The morphology of the human prostate is more compact, without distinct lobes, and is divided into three zones: central, transitional, and peripheral (McNeal, 1983).

Some murine species of the subfamily Gerbillinae have been utilized as models for studies of the male reproductive tract. Among them stand out Praomys natalensis (Gross and Didio, 1987), Psammomys obesus (Sprando et al., 1999), and Meriones unguiculatus (Williams, 1974), the last species being known as the Mongolian gerbil.

The gerbil's prostate has a similar morphology to that of the human gland with respect to the fusion of its lobes in a compact structure, unlike the prostate of mice and rats. However, more specific data on the prostate of these murines have not been found in current literature. It is therefore of interest to know more about the prostate structure of this animal, especially since, although several rodent models exist for the study of the normal morphological aspects and proliferative alterations in the prostate, at this moment, none is completely effective in representing aspects of human prostate cancer (Bostwick et al., 2000; Shirai et al., 2000; Wang et al., 2001).

In the present study, we characterized the histological, ultrastructural, and quantitative behavior of the gerbil ventral prostate in three phases of postnatal development (young, adult, and old). Our goal was to improve our understanding of prostate biology in this animal species besides its propensity to develop spontaneous lesions with aging.

\section{MATERIALS AND METHODS Animal and Sample Preparations}

Male gerbils, being 10 young (with $48 \pm 15.9$ days of mean age $), 10$ adults (112 \pm 27.7 days $)$, and 10 old (18 \pm 5.4 months), were housed under conventional conditions $\left(25^{\circ} \mathrm{C}, 40-70 \%\right.$ relative humidity, $12-\mathrm{hr}$ light/12-hr dark) and allowed access to chow and water ad libitum. The animals were placed in a chamber with $\mathrm{CO}_{2}$ gas prior to sacrifice. After this, the entire prostatic complex was excised and the ventral prostate removed and cut into fragments. For light microscopy, the samples were fixed for 24 hr in Karnovsky solution (0.1 M Sörensen phosphate buffer, pH 7.2, containing 5\% paraformaldehyde and $2.5 \%$ glutaraldehyde). After fixation, the material was dehydrated in graded ethanol series and the embedding was performed in glycol methacrylate resin (Leica historesin embedding kit).

\section{Structural Analysis}

The $3 \mu \mathrm{m}$ histological sections were submitted to hematoxylin-eosin (H\&E) staining for general morphological analysis, Gömöris reticulin staining for collagen and reticular fibers, Feulgen reaction for nuclear phenotypes, and AgNOR for nucleolus study. The microscopy analyses were performed with Zeiss-Jenaval or Olympus photomicroscopes. The Image-Pro Plus software version 4.5 for Windows software was used to digitalize the images of each histological section.

\section{Transmission Electron Microscopy (TEM)}

Ventral prostatic fragments were fixed by immersion with $3 \%$ glutaraldehyde plus $0.25 \%$ tannic acid solution in Millonig's buffer, $\mathrm{pH} 7.3$, containing $0.54 \%$ glucose for 24 hr (Cotta-Pererira et al., 1976). After washing with the same buffer, they were postfixed with $1 \%$ osmium tetroxide for $2 \mathrm{hr}$, washed again, dehydrated in graded acetone series, and embedded in Araldite resin. Ultrathin sections were cut using a diamond knife and contrasted with $2 \%$ alcoholic uranil acetate for $30 \mathrm{~min}$, followed by $2 \%$ lead citrate in sodium hydroxide solution for $10 \mathrm{~min}$. The samples were observed and evaluated with a LEO-Zeiss 906 transmission electron microscope.

\section{Quantitative Analysis}

Thirty random prostatic areas of each of the three phases of postnatal development staining by H\&E sections were analyzed. The morphometric-stereological analyses were carried out using Weibel's multipurpose graticulate with 120 points and 60 test lines (Weibel, 1978) to compare the relative proportion (\%) of the gland portions (glandular and stromal) and each prostatic tissue constituent (epithelium, lumen, nonmuscular interacinar stroma, smooth muscle cell, and collagen subepithelial layer). For the morphometric analyses, 200 random measurements of the epithelium height and the thickness of the smooth muscle layer that surrounds each acinum were also obtained.

Caryometric evaluation was carried out using Feulgen reaction-stained sections. Nuclear areas, perimeters, and the form factor $\left.[=4 \pi \times \text { nuclear area/(nuclear perimeter })^{2}\right]$ parameter were determined for 200 nuclei of the epithelial secretory cells in each phase. The form factor parameter measures nuclear roundness in such a way that values $<$ 1 are associated with nuclei that are more rounded (Taboga et al., 2003).

Nuclei with the following numbers of nucleoli-zero (not observed), one, two, and more than two-were counted in 25 fields selected by group of animals. The absolute values found were converted into percentages. The nucleolus number/nucleus age ratio was calculated and 30 area and perimeter measurements of nuclei and nucleoli simultaneously in each group were also taken. This parameter was adopted in order to verify whether the quantitative alterations suffered by the areas and nucleolar perimeters of the secretory cells were proportional to those suffered by the nuclei. All measurements were obtained using the Image-Pro Plus program version 4.5 for Windows.

\section{Serum Testosterone Concentration}

Blood samples were collected from each animal group. The serum was separated by centrifuge at 3,000 rpm and 
stored until assayed. Testosterone concentration was determined by automatic equipment (VITROS ECi-Johnson and Johnson Ultra-Sensitive Quimioluminescent analysis) in a renowned clinical analysis laboratory using specific reagents supplied by Johnson and Johnson Orthoclinical. The sensitivity of this assay was $0.1-150.0 \mathrm{ng} / \mathrm{ml}$.

\section{Statistical Analysis}

All statistical analyses were performed with Statistica 6.0 software (StatSoft). The ANOVA and Tukey honest significant difference (HSD) tests were applied and $P \leq$ 0.05 was considered statistically significant.

\section{RESULTS \\ Prostate Structure and Ultrastructure}

In postnatal phases, the gerbil prostate develops a branched alveoli and ducts resembling a tubuloacinar gland. The stroma was composed of smooth muscle cells (SMCs), collagen, and elastic fibers and blood vessels (Fig. $1 \mathrm{~A}, \mathrm{D}$, and $\mathrm{G}$ ).

In the young animal, the ventral prostate is an immature gland (Fig. 1A and B) composed of some acini still in the process of glandular modeling (Fig. 1B); the majority of the acini with defined ductal canalization and epithelial layer are arranged in such a way as to surround the narrow lumen (Fig. 1A). The epithelium is composed of voluminous cells with prominent nuclei occupying large portions of the cell (Fig. 1B and 2A). Ultrastructurally, the nuclear chromatin remains descondensed, suggesting synthetic activity. In the cytoplasm, a relative scarcity of synthesis organelles confirms the generally undifferentiated state of the epithelial cells (Fig. 2B). Specializations of the membrane, such as adherent junctions, may be found uniting such cells and a basement membrane separates the epithelium from the stromal compartment (Fig. $2 \mathrm{C}$ and $\mathrm{D})$.

The stroma of the young animal was composed of two cellular types: SMC and fibroblasts (Fig. 2A). Among the fibrilar elements of the extracellular matrix, collagen and reticular fibers are found in large quantities, forming a sustentation net for the prostate gland (Fig. 1C). Ultrastructurally, the collagen fibrils are accumulated at the epithelium base and dispersed throughout the stroma, including between SMC, being disposed in different directions (Fig. 2D, E, F, and H). The SMCs are arranged in an expansive layer around each acinus (Fig. 1A and B) and they also join in a differentiation process with a nucleus and a dilated cytoplasm with low electrondensity and poor contractile elements (Fig. $2 \mathrm{~F}$ and G). The fibroblasts have a functional phenotype distributed at the base of the epithelium and among the muscle cells (Fig. 2A and E). Few elastic fibers were found to be associated with the cell surface of the fibroblasts (Fig. 2E) and/or involved in the SMC cytoplasmic process (Fig. $2 \mathrm{H}$ ).

In the adult animal, the ventral prostate was recognized as a completely developed gland, with a wide acinar lumen, which indicates intense secretory activity, and with secretory epithelial cells (Fig. 1D) disposed in a simple columnar pattern (Fig. 1E). The epithelium, at the ultrastructural level, is composed of two cellular lineages, secretory and basal cells (Fig. 3A and B). The secretory cells remain in contact with the glandular lumen and have a cytoplasm with a well-developed rough endoplasmic reticulum, Golgi apparatus, mitochondria, and secretion vesi- cles at the apical pole (Fig. 3A, C, and D). Their nuclei are bulky, with uniform outlines and deposits of condensed chromatin in the peripheral region (Fig. 3B and D). The inconspicuous basal cells localized along the basement membrane have a largely undifferentiated phenotype with no secretory bleb production (Fig. 3B).

The SMCs acquire a fusiform phenotype shape, forming concentric layers and strongly packed layers around the acini with small intercellular spaces (Figs. 1D and E and $3 \mathrm{~F}$ ), which were occupied by collagen fibrils (Fig. $3 \mathrm{~F}, \mathrm{H}$, and I). The nuclei of the SMCs usually accompany the shape of the cell and the cytoplasms are abundant in contractile filaments (Fig. 3G). The fibroblasts are located preferentially at the base of the epithelium (Fig. 3F) and, in some areas, their projections establish a close contact with SMCs (Fig. 3H). The reticular fibers diminish accompanying the more slender pattern of the smooth muscle layer, and collagen fibers were found to form an approximately concentric subepthelial layer, as verified by the Gömöri method (Fig. 1F). Elastic fibers were observed to be bare and organized as short fibers associated with the collagen fibrils at the base of the epithelium (Fig. 3E) and/or deposited in the thicker layer around the muscle cells (Fig. 3I), maintaining contact with their membranes.

The prostate gland of the old animals was characterized by morphologically heterogeneous areas. In a single gland, there were sites with a secretory epithelium functionally (Figs. 1G and $\mathrm{H}$ and $4 \mathrm{~A}$ ) similar to that found in adult animals, with some secretory cells maintaining marked secretion liberation in their apex (Figs. $1 \mathrm{H}$ and $4 \mathrm{C}$ ), while in others, there were altered sites with a hyperplastic increase in epithelial cells (Fig. 1I). In the latter case, infoldings of the epithelium into the luminal spaces could be observed, as well as cells with phenotypic alterations (Fig. 1J) characterizing prostatic intraepithelial neoplasia (PIN; including pale cytoplasm and nuclear pleomorphism). In addition, secretory cells were observed to have fatty deposits distributed by the whole cytoplasm (Fig. 4B) and osmiophylic deposits resembling lipofuscin, indicative of cellular aging (Fig. 4C). The basal cells maintained their morphological characteristics and they also had lipofuscin-like and ceramide-like deposits (Fig. 4D). In senescence, the main alteration in the prostatic stroma was the fibrilar component remodeling of the extracellular matrix. This process involved a marked increase in the number of collagen fibers, which formed a wide subepithelial accumulation, including infoldings (Fig. $1 \mathrm{H}$ and $\mathrm{L}$ ) and an increase in reticular fibers. This loose rearrangement contributed an alteration in the distribution of the muscular layer around many acini (Fig. 1L), but the majority of the SMCs maintained their fusiform shapes (Fig. 1H). Some exhibited an irregular external outline, nuclear shrinkage, and great mitochondria in the perinuclear area (Fig. $1 \mathrm{~F})$. The increase in the number and thickness of collagen fibrils among the SMCs also contributed to a larger separation between them (Fig. $4 \mathrm{E}$ and $\mathrm{F}$ ).

\section{Quantitative Analysis}

The data regarding quantitative analysis are set out in Tables 1 and 2. As regards stereological parameters (Table 1 ), the proportions of the epithelial and stromal compartments of the ventral prostate in the young group were different from those of the other groups, because the glandular lumens were not so significant. At the same time, the proportion of the stromal compartment was greater 

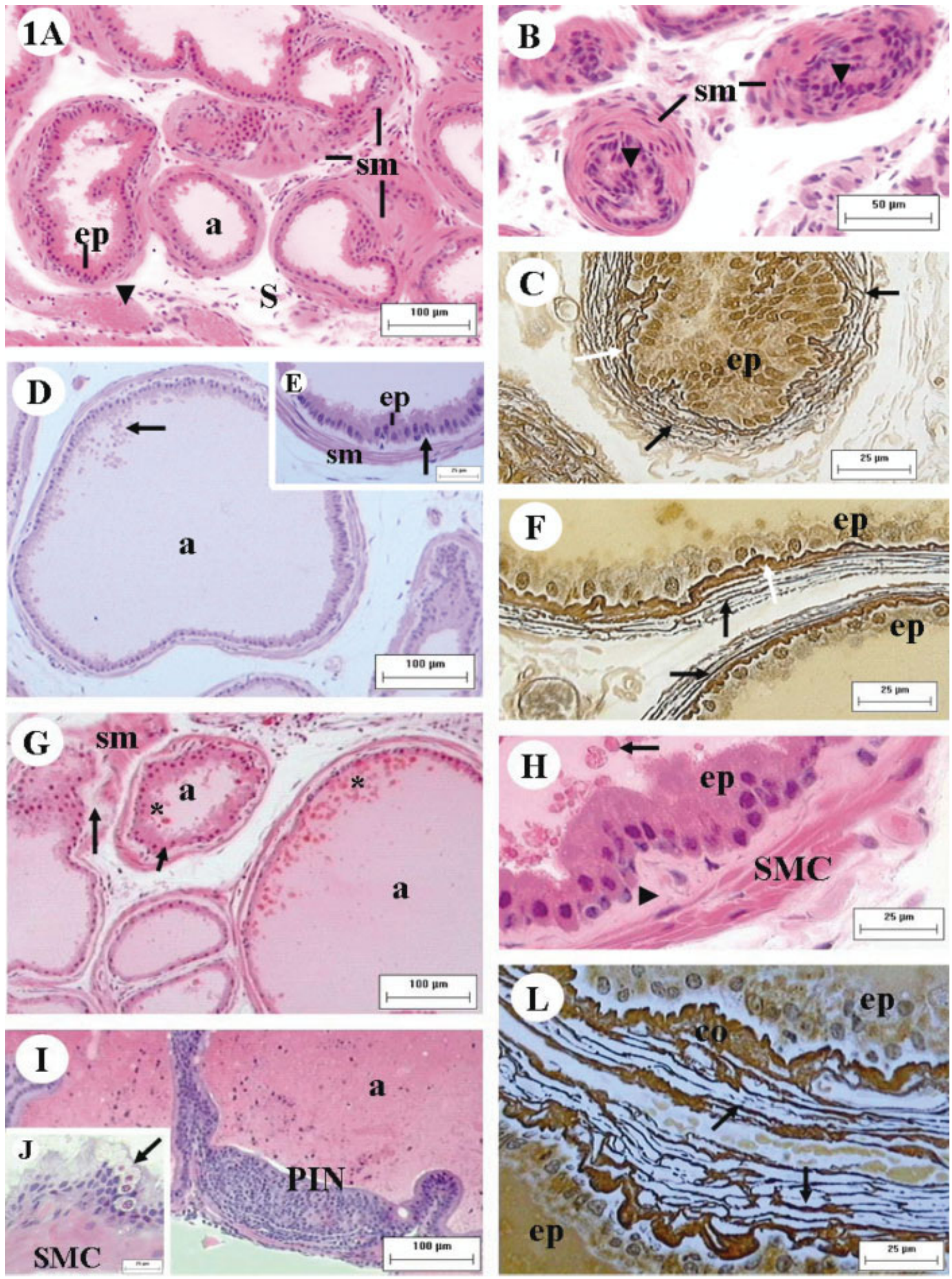

Fig. 1. A, B, D, E, G-J: Hematoxylin-eosin stain. A-C: Young group. A: General vision of the ventral prostate of the young gerbil constituted by the epithelial (ep) and stromal compartments (S) organized in small acini (a) surrounded by a thick smooth muscle (sm). Arrowhead indicates vessel. B: Detail of acini with epithelial cells exhibiting voluminous nuclei (arrowhead). C: Dense arrangement of thin reticular fibers (white arrow) in base of epithelium and interspersed with SMC (arrows). D-F: Adult group. D: General aspect of acinus with wide acinar lumen active in secretion production (arrow). E: Secretory epithelium composed of columnar cells surrounded by compacted smooth muscle layer. Note collagen deposit at the epithelium base (arrow). F: Disposal of thin reticular fibers in a more densely packed arrangement than that of young animals (arrows). Collagen deposit (white arrow) at the base of epithelial structure. G-L: Old group. G: Decreased interacinar spaces; some acin with evident secretory activity (asterisk) intercalated by acini with larger collagen accumulation (arrows) in the subepithelial region and allocated irregularly smooth muscle. H: Denser and undulated epithelium, increased density of subepithelial collagen (arrowhead) and thicker SMC. Arrow indicates secretion, blebs. I: Acinus with high epithelial proliferation characterizing a PIN. J: Detail of cells related to the proliferative aggregate exhibiting altered phenotypes and pale basophilic cytoplasm (arrow). L: Increased denser reticular fibers (arrows) disposed in loose network accompanying SMC distribution. C, F, and L: Gömöri's reticulin method. 

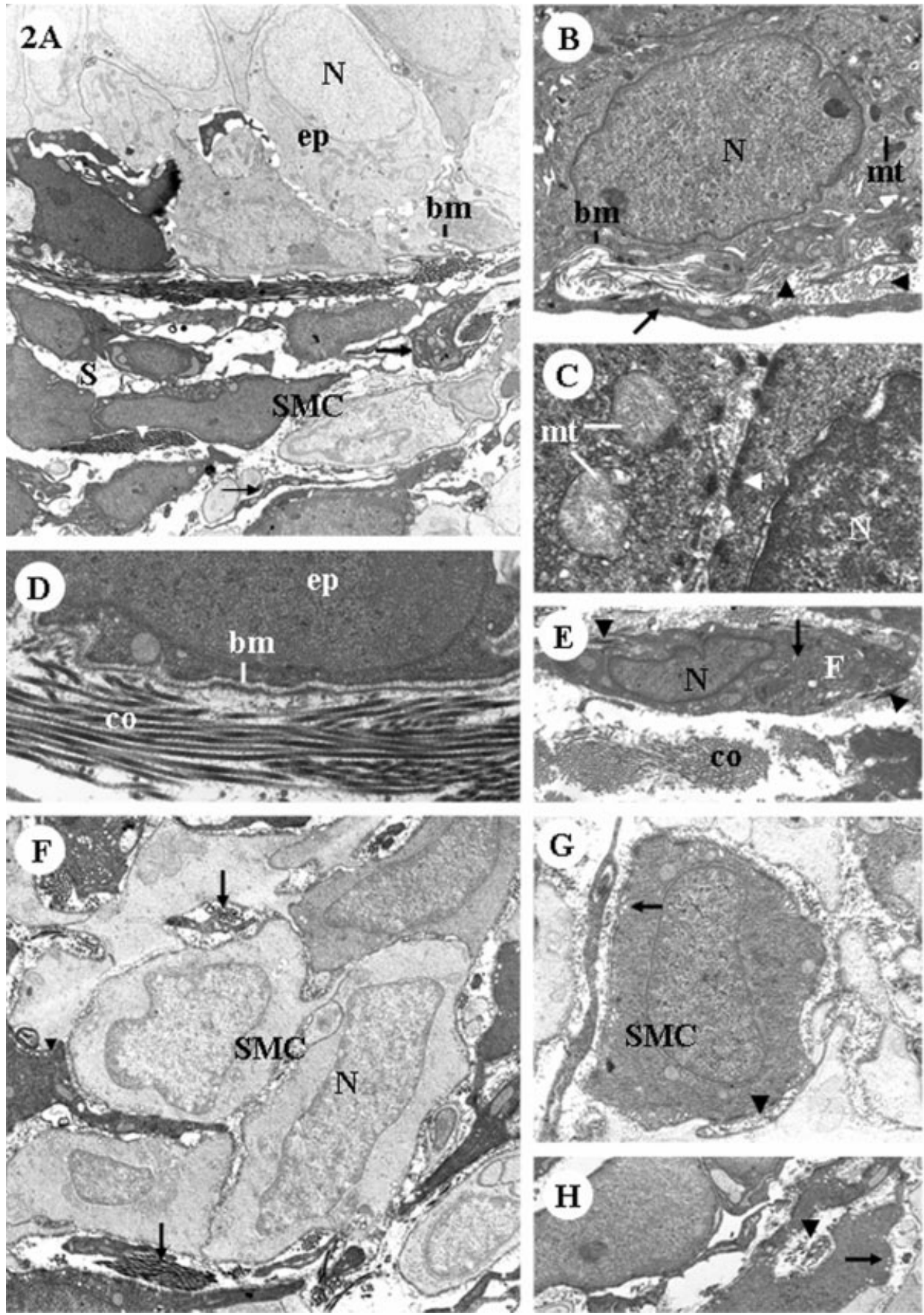

Fig. 2. Ultrastructure of the young ventral prostate. A: Epithelium (ep) composed of immature epithelial cells with copious nuclei $(\mathrm{N})$ and in the stroma (S), largely well-spaced undifferentiated SMCs. The fibroblasts (arrows) emit cytoplasmic projections throughout stroma. Arrowhead, collagen fibrils; bm, basement membrane. Magnification: 3,597 $\times$. B: Immature epithelial cell with voluminous nucleus and descondensed chromatin. mt, mitochondrias. Collagen fibrils (arrowhead) distributed in different directions in the interface between epithelium and stroma associated with fibroblast projection (arrow) and basement membrane. Magnification: $7,750 \times$. C: Detail of the adherent junctions uniting two epithelial cells (arrowheads). mt, large mitochondrias. Magnification:
35,970×. D: Collagen fibrils (co) transversally arranged below the epithelium intimately associated with basement membrane. Magnification: $16,700 \times$. E: Fibroblast with prominent nucleus and in association with elastic fibers (arrowhead). Magnification: 7,750×. F: SMCs are extensive, poor in contractile element and are not densely packed. Collagen fibrils (arrows) and fibroblast process (arrowhead) are inserted between them. Magnification: 7,750×. G: More electrondense SMCs, and caveolae (arrow) in the cell membrane, indicating advanced differentiation process. Magnification: $12,930 \times$. H: Detail of SMCs showing elastic fibers inside their cytoplasmic process (arrowhead). Arrows indicate caveolae. 

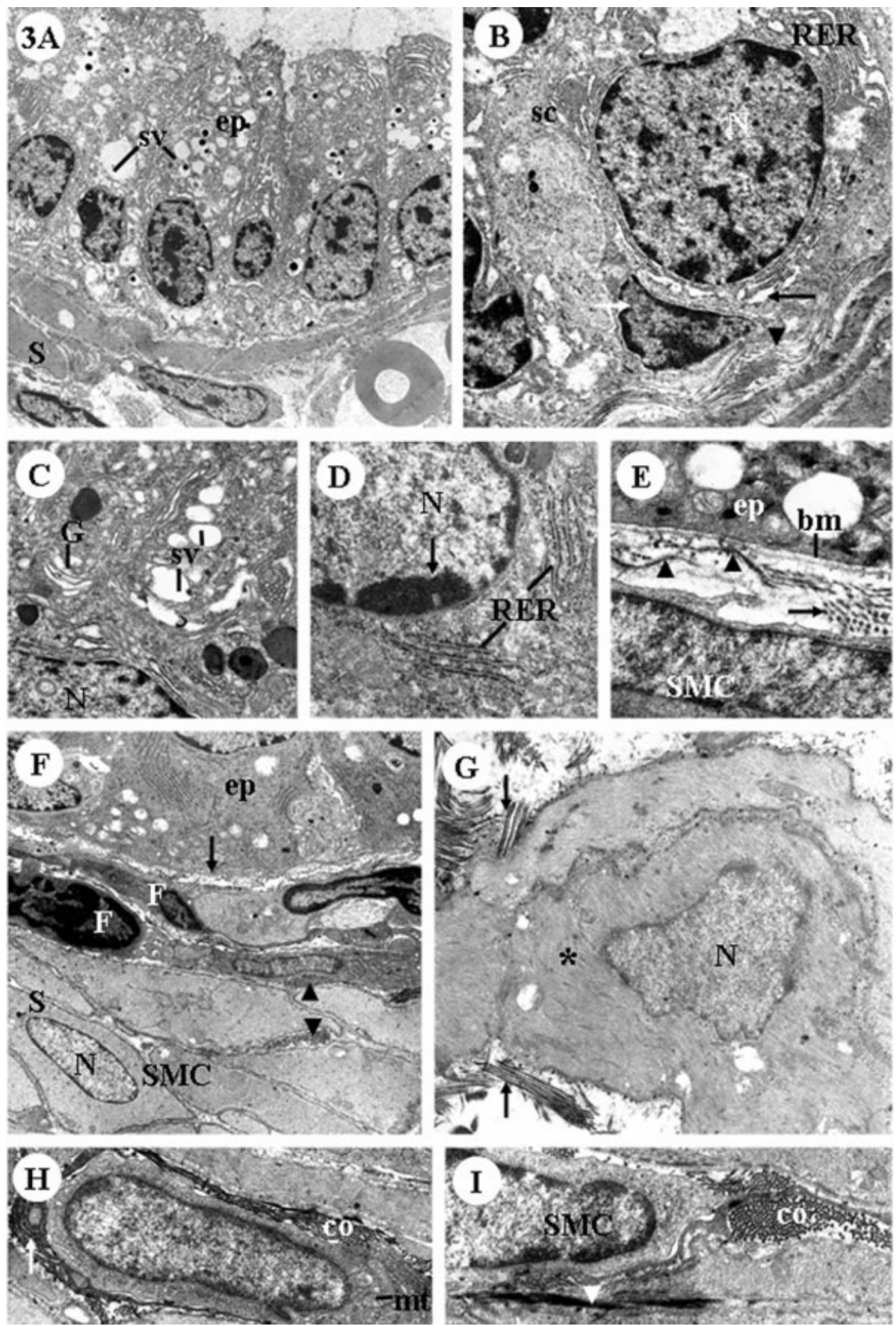

Fig. 3. Ultrastructure of the adult ventral prostate. A: Epithelial cells (ep) with numerous secretory vesicles (sv) in the cytoplasm. S, stroma. Magnification: 3,597×. B: Two cell types form the prostate epithelium, the secretory (sc) and basal cells (white arrow). RER, endoplasmic reticulum cisternae (black arrow). The latter are smaller, have fewer synthesis organelles, and the nucleus occupies most of the cell. Arrowhead indicates basement membrane. Magnification: 10,000×. C: Abundant Golgi stacks (G) and secretory vesicle in cytoplasm of secretory cell. Magnification: 16,700×. D: Endoplasmic reticulum cisternae in the perinuclear region. Deposit of condensed chromatin in nuclear periphery (arrow). Magnification: 27,800×. E: Collagen (arrow) and elastic fibers (arrowhead) associated with basal membrane $(\mathrm{bm})$ in the interface be-

tween epithelium and stroma. F: Stroma composed of fibroblasts (F) localized below glandular epithelium and packed SMC layer with reduced spaces between the cells, occupied by collagen fibrils (arrowhead). Basement membrane (arrow). Magnification: 6,000×. G: Differentiated SMCs exhibiting abundant contractile elements (asterisks) surrounded by collagen fibrils disposed in several directions (arrow). Magnification: 7,750×. H: Fusiform SMCs with large nucleus accompanying cell shape and surrounded by fibroblast process (arrow). co, collagen fibrils; mt, mitochondrias. Magnification: $10,000 \times$. I: Detail of SMCs in close contact with collagen (co) and elastic fibers (arrowhead). Magnification: $12,930 \times$. 

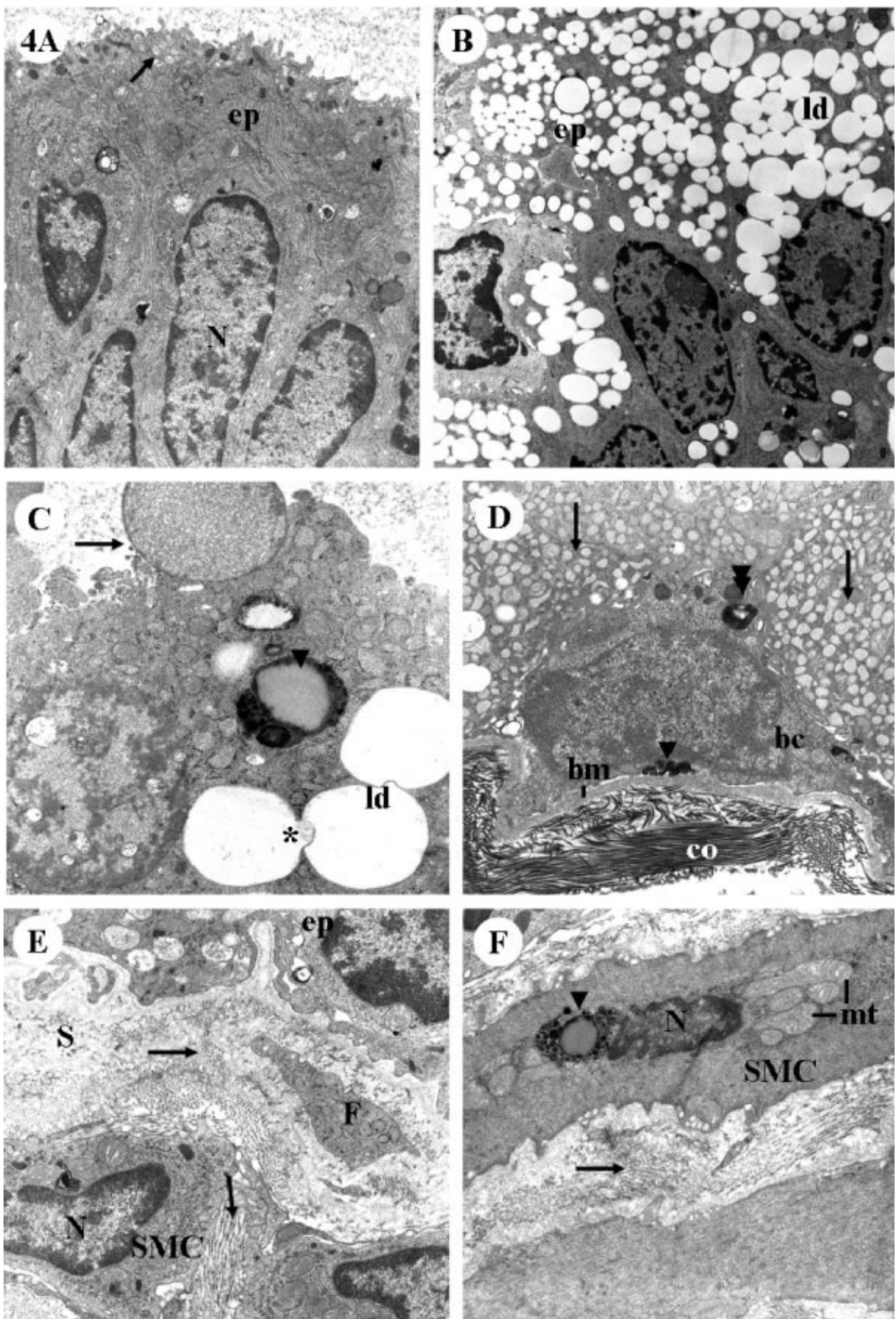

Fig. 4. Ultrastructure of old ventral prostate. A: Site of normal secretory epithelial cells (ep) with secretory vesicle in the apex (arrow). Magnification: $7,750 \times$. B: Site of epithelial cells with marked accumulation of lipid droplets (Id), a frequent event during gerbil aging. Magnification: $4,646 \times$. C: Apical portion of a secretory cell with bleb (apocrine secretion, arrow), integrated lipid droplets (asterisk), and lipofuscin-like structure (arrowhead). Magnification: 16,700×. D: Basal cell (bc) with large nuclei and few synthesis organelles, in the nuclear periphery ceramidelike (arrowhead) and lipofuscin-like deposits (double arrowhead), sur- rounded by secretory cells full of secretory vesicles (arrow). A thick basement membrane $(\mathrm{bm})$ delimits the epithelium of the stroma, below which is a larger deposit of collagen fibrils (co), another mark of the aging process. Magnification: 10,000×. E: Stroma (S) showing increase of collagen fibrils in subepithelial area (arrows) and between SMCs, which maintain condensed cytoplasm. F, fibroblast. Magnification: 12,930×. F: SMCs with irregular and compressed nucleus in the nuclear periphery. Lipofuscin-like structure (arrowhead) and remarkably extensive mitochondrias (mt). Arrow indicates collagen fibrils. Magnification: 16,700×. 
TABLE 1. Values of the morphometric-stereological data in the gerbil ventral prostate in three phases of postnatal development

\begin{tabular}{|c|c|c|c|}
\hline \multirow[b]{2}{*}{ Prostatic Measurements } & \multicolumn{3}{|c|}{ Groups } \\
\hline & $\begin{array}{c}\text { Young } \\
(48 \pm 15.9 \text { days })\end{array}$ & $\begin{array}{c}\text { Adult } \\
(112 \pm 27.7 \text { days })\end{array}$ & $\begin{array}{c}\text { Old } \\
(18 \pm 5.4 \text { months })\end{array}$ \\
\hline Testosterone levels (ng/mL)* & $3.95 \pm 0.57^{\mathrm{a}}$ & $4.82 \pm 0.33^{\mathrm{b}}$ & $2.80 \pm 0.23^{c}$ \\
\hline $\begin{array}{l}\text { Density of Compartment (\%) } \\
\text { Glandular Epithelial } * * *\end{array}$ & $34.64 \pm 13.10^{\mathrm{a}}$ & $56.33 \pm 11.24^{\mathrm{b}}$ & $60.95 \pm 12.14^{\mathrm{b}}$ \\
\hline Stromal*** & $65.36 \pm 13.10^{\mathrm{a}}$ & $43.67 \pm 11.24^{\mathrm{b}}$ & $39.05 \pm 12.14^{\mathrm{b}}$ \\
\hline $\begin{array}{l}\text { Volume of tissue components (\%) } \\
\text { Epithelium** }\end{array}$ & $22.00 \pm 6.60^{\mathrm{a}}$ & $14.77 \pm 4.76^{\mathrm{b}}$ & $22.20 \pm 7.04 \quad$ a \\
\hline Lumen $* * *$ & $12.64 \pm 9.87^{\mathrm{a}}$ & $41.56 \pm 11.99^{b}$ & $38.74 \pm 13.96^{\mathrm{b}}$ \\
\hline Smooth muscle cells*** & $27.72 \pm 7.82^{\mathrm{a}}$ & $16.18 \pm 6.42^{\mathrm{b}}$ & $14.23 \pm 7.74^{\mathrm{b}}$ \\
\hline Colagen subepithelial layer $* * *$ & $1.10 \pm 1.66^{\mathrm{a}}$ & $3.08 \pm 2.59^{\mathrm{a}}$ & $5.43 \pm 4.64^{\mathrm{b}}$ \\
\hline $\begin{array}{l}\text { Non-muscular interacinar stroma** } \\
\text { Morphometry - Thickness }(\boldsymbol{\mu} \mathbf{m})\end{array}$ & $36.54 \pm 11.94^{\mathrm{a}}$ & $24.41 \pm 11.83^{\mathrm{b}}$ & $19.38 \pm 7.81^{b}$ \\
\hline Epithelium $* * *$ & $14.83 \pm 3.31^{\mathrm{a}}$ & $11.11 \pm 2.33^{\mathrm{b}}$ & $18.53 \pm 4.22^{\mathrm{c}}$ \\
\hline Smooth muscle layer*** & $17.17 \pm 4.41^{\mathrm{a}}$ & $12.09 \pm 3.69^{b}$ & $15.14 \pm 5.15^{\mathrm{c}}$ \\
\hline $\begin{array}{l}\text { Nuclear and nucleolar morphometry } \\
\text { Nuclear area }\left(\mu \mathrm{m}^{2}\right)^{* * *}\end{array}$ & $24.16+50^{\mathrm{a}}$ & $21 \mathrm{a}+48^{\mathrm{b}}$ & $547^{\mathrm{a}}$ \\
\hline Nuclear perimeter $(\mu \mathrm{m}) * * *$ & $\begin{array}{l}24.16 \pm 5.0^{\mathrm{a}} \\
20.24 \pm 2.30^{\mathrm{a}}\end{array}$ & $\begin{array}{l}21.92 \pm 4.48 \\
18.86 \pm 2.14^{b}\end{array}$ & $\begin{array}{l}24.58 \pm 5.4 \gamma^{\mathrm{a}} \\
20.12 \pm 2.53^{\mathrm{a}}\end{array}$ \\
\hline Nuclear Form Factor* & $0.74 \pm 0.09^{a}$ & $0.77 \pm 0.01^{b}$ & $0.76 \pm 0.10^{\mathrm{b}}$ \\
\hline Nucleolar Area $\left(\mu \mathrm{m}^{2}\right)^{*}$ & $0.91 \pm 0.50^{\mathrm{a}}$ & $1.31 \pm 0.44^{\mathrm{b}}$ & $1.30 \pm 0.53^{b}$ \\
\hline Nucleolar perimeter $(\mu \mathrm{m})$ & $4.35 \pm 2.13$ & $4.73 \pm 1.29$ & $4.21 \pm 1.18$ \\
\hline Nucleolus/Nucleus ratio & & & \\
\hline Area & $0.04 \pm 0.02$ & $0.06 \pm 0.02$ & $0.05 \pm 0.02$ \\
\hline Perimeter & $0.22 \pm 0.09$ & $0.25 \pm 0.07$ & $0.20 \pm 0.05$ \\
\hline
\end{tabular}

Values represent mean \pm SD. Statistical analysis basead on the Anova and Tukey Tests. Significance, $* p \leq 0.01 ; * * p \leq 0.001 ;$ $* * * \mathrm{p} \leq 0.0001$.

a, b, ${ }^{c}$ Different superindices indicate inter-group significant differences.

TABLE 2. Percentage distribution of the nuclei by nucleolus number in secretory epithelial cells in the gerbil ventral prostate in three phases of postnatal development

\begin{tabular}{|c|c|c|c|c|c|}
\hline \multirow[b]{3}{*}{ Groups } & \multicolumn{5}{|c|}{$\%$ of nuclei containing each number of nucleoli ( 0 , Nucleolus no observed) } \\
\hline & \multicolumn{5}{|c|}{ Number of nucleoli in each nucleus } \\
\hline & $0^{*}$ & 1 & $2^{*}$ & More than $2 *$ & $\begin{array}{c}\text { Average number of } \\
\text { nucleoli in group* }\end{array}$ \\
\hline Young & $43.20 \pm 2.34^{\mathrm{a}}$ & $40.72 \pm 2.19$ & $10.40 \pm 1.91^{\mathrm{a}}$ & $5.69 \pm 1.61^{\mathrm{a}}$ & $0.78 \pm 0.05^{\mathrm{a}}$ \\
\hline Adult & $53.56 \pm 2.45^{\mathrm{b}}$ & $42.03 \pm 2.52$ & $3.66 \pm 0.91^{b}$ & $0.74 \pm 0.36^{b}$ & $0.51 \pm 0.03^{b}$ \\
\hline Old & $49.91 \pm 2.58^{\mathrm{a}, \mathrm{b}}$ & $41.26 \pm 2.28$ & $4.96 \pm 1.21^{b}$ & $3.86 \pm 0.97^{\mathrm{a}, \mathrm{b}}$ & $0.63 \pm 0.04^{b}$ \\
\hline
\end{tabular}

Values represent mean \pm ED. Statistical analysis basead on the Anova and Tukey Tests. Significance, $* \mathrm{p} \leq 0.01$.

a, bDifferent superindices indicate inter-group significant differences.

due to the larger percentage of the nonmuscular interacinar stroma and SMCs. In the adult and senile phases, the prostate epithelial and stromal compartments were of similar stereological proportions. However, the percentages of epithelial tissue and the nonmuscular subepithelial stroma (collagen layer) increased significantly with aging while the nonmuscular interacinar stroma decreased. The thickness of the epithelium and the smooth muscular layer varied significantly during development, the lowest measurements being found in the adult stage. The significant increase in these measurements during aging confirms the occurrence of glandular hyperplasia during this phase, a process verified by histochemical evaluation.

The area and perimeter nuclear values of the secretory cells (Table 1) showed that both measurements were significantly higher in young and old animals than in adults, which indicates a distinct degree of nuclear function in relation to age throughout development. As in the case of the other parameters analyzed, the nuclear measurements increased in the old animals, suggesting an increase and/or reincidence of secretory cell activity with the aging. The factor form value obtained was 0.7 in all three phases, indicating a circular form of the nuclei.

In all three phases, the majority of the secretory cell nuclei either had no evident nucleolus or exhibited nuclei with a single nucleolar corpuscle (Table 2). The young animals presented the largest percentages of nuclei, with two or multiple (more than two) nucleoli and consequently a larger mean number of nucleoli per nucleus in relation to the two other phases, indicating high proliferative activity. However, these parameters were not correlated proportionally by the area and perimeter nucleolar measurements (Table 1), and the total nucleolar area of the young group was smaller in relationship to that of the other two groups. The mean values of the perimeter and nucleolus/nucleus ratios for these parameters did not vary significantly throughout postnatal development, suggest- 
ing uniform functional behavior of these organelles in all three phases.

Serum testosterone levels varied significantly $(P \leq 0.05)$ between young, adult, and old animals, which confirmed an expected decrease in hormonal concentrations in the oldest group (Table 1).

\section{DISCUSSION}

The ventral prostate of the gerbil Meriones unguiculatus was evaluated morphologically and quantitatively throughout postnatal development. This gland structure, as in other rodents, consists of two ventrolateral lobes adjoining the urinary bladder, attached to the urethra by a series of ducts, smooth muscle, and connective tissue (Shirai et al., 2000; Suwa et al., 2001).

The prostate morphology of the young animals presented a distinct organizational pattern when compared to that of the adult and old animals. The quantitative analysis of the epithelial and stromal components, as well as of the thickness of the secretory epithelial and muscular layers, corroborated the existent morphological differences. At an age between 1 and 2 months, the prostate is an immature gland, with limited secretory activity. As in other mammals, the development, differentiation, and activity of the prostate depend on androgens and interactions between the epithelial and estromal compartments (Cunha et al., 1986; Banerjee et al., 2000; Taplin and Ho, 2001). As the organogenesis of the gland occurs during periods of relatively low serum androgenic levels, which persist until puberty (Thomson, 2001), we wished to accompany prostate development from the beginning of postnatal life under the effects of a low-hormone milieu.

Ventral prostate activity was found to be stable in adult and old animals. However, the general morphology of the gland was varied between those ages. In adults, the prostate was a completely functional gland with an intense amount of synthesis organelles in the secretory cell cytoplasm and an accumulation of secretion products in the acinar lumen, which made this prostate component the most representative. The lower number of basal cells was dispersed in a discontinuous layer and exhibited a largely undifferentiated phenotype, as in other rodents. The specific function of the basal cells is still not clear. However, several studies indicate them as prostate epithelial stem cell candidates (Garraway et al., 2003; Marker et al., 2003). Intermixed with the glandular portions was a conjunctive stroma, where smooth muscular cells enclosed each acinus individually. Together with the fibroblasts, these cells are related to the expulsion of acinar secretions during ejaculation and also to the synthesis of structural and regulatory components of the extracellular matrix (Horsfall et al., 1994; Tuxhorn et al., 2001). Supporting the observed results, the stroma fibrillar components (collagen and elastic fibers) were connected to each other and also to the cellular components of the prostate and probably serve the role of guaranteeing the structural integrity of this organ. These fibrils must also participate in SMC contraction and elastic restoration during the normal functioning of the gland (Carvalho et al., 1997). The most significant difference between the human and the murine prostate is that, in humans, there are significantly more fibromuscular stroma, while in mice, the glands are surrounded by a loose connective tissue (Roy-Burman et al., 2004). The gerbil's fibromuscular stroma was also looser. However, the participation of the stromal elements in gerbil prostatic development and functionality is similar to that of the stromal components in the human prostate. As observed by Thomson (2001), the maintenance of prostatic morphology and secretory activity during the adult phase is dependent on high androgen levels, as opposed to initial postnatal period, which indicates a change in androgenic response throughout the development stages.

The general and ultrastructural morphology of the ventral prostate alters with senescence, although the secretory activity of the organ remains regular in spite of low levels of testosterone. Comparing adult and old animals, it was possible to confirm the main tissue alterations that occur in the ventral prostate during aging. The majority of the morphological alterations were quantitatively confirmed by statistical analysis. In most of the acini, an increase in the number of epithelial cells was confirmed and, in some cases, PIN occurred, contributing to a significant increase in glandular epithelial percentage during aging. Many authors consider PIN to be the precursor of prostatic carcinogenesis. Possible origins of PIN might be abnormal cellular differentiation, aberrant expression of growth factor receptors, and controlling genes of cellular growth and differentiation (Bostwick et al., 1996; Bonkhoff and Remberger, 1998). A common feature in the secretory cells was lipid accumulation in the whole cytoplasm. Swinnen et al. (1997) verified a similar process in the human prostatic adenocarcinoma cell line LNCaP. In these cells, the cytoplasmic lipid droplets mainly consist of products of fatty acids and cholesterol, being the expression of lipogenic enzymes regulated by androgens. These lipid droplets can also be related to the peroxidation of unsaturated fatty acids, common in several tissues during aging (Alho et al., 1989). These deposits may have contributed to cellular expansion and a consequent thickening of the epithelial layer. Osmiophylic structures were occasionally found in the pericellular space in all cellular types, which seem to be ceramide-like deposits. The ultrastructure of these bodies was described in the gerbil prostate after finasteride therapy by Corradi et al. (2004) Ceramide generation has been considered to be a critical component in radiation-induced apoptosis in human prostate cancer cells (Kimura et al., 1999).

As cellular and nuclear morphometry are still reliable prognostic factors in the evaluation of human prostate pathologies (Taboga et al., 2003), and it is our intention to evaluate spontaneous alterations occurring during gerbil aging, the secretory cell measurements obtained during the current research will serve as comparative controls in future studies. The nuclei of the secretory cells of young and old animals, whose higher area and perimeter values indicated greater activity of these organelles than in adult animals, also affected variations in the thickness of the epithelium according to age. The alterations observed in nuclear morphometry were not reflected in the factor forms, which gave a value close to 1 in all age groups. It should be mentioned that the degree of nuclear pleomorphism aids in the prognostic of prostate cancer (Zhang et al., 2000), and neoplasic cells typically have enlarged nuclei with prominent nucleoli (Roy-Burman et al., 2004). In the present study, in the old animals, there was a tendency toward heterogeneity in nuclear form and size, mainly in PINs, although this was not significant.

The young animals were found to have a larger number of nucleolar corpuscles per nucleus than was the case in the other groups. However, the morphometric values of 
these structures did not differ significantly between the groups, indicating uniform behavior of the organelle throughout the three phases of development. The nucleolus/nucleus ratio showed that dimensional variations undergone by the nuclei are accompanied by the nucleoli, which have a functional complementation among these organelles. Nucleolar DNA content is an indicator of functional condition and the degree of cellular proliferation (Karalyan et al., 2004). Studies have shown that quantitative analysis of AgNOR proteins provides additional information concerning the biological behavior of tumors, being an independent prognostic factor (Ceccarelli et al., 2000; Öfner, 2000).

In the senile animal, the stromal compartment proportions were a little smaller in relation to those of the other age groups. However, increases in the thickness of the smooth muscular layer and the subepithelial collagen fibers, as well as a decrease in the interacinar spaces, combined to make the compartment more abundant in fibromuscular composition. Similar alterations occurred in the adult gerbil ventral prostate when treated with finasteride, with a spreader arrangement of the smooth muscle and the wavy or sinuous collagen fibers (Corradi et al., 2004). In human stromal culture cells, a differential growth rate and cellular shape changes occur with increasing donor age and/or the development of benign prostatic hyperplasia (BPH), indicating that there may be an inherent difference in prostate stromal composition with age (Sensibar et al., 1999). Alterations in the form, amount, and distribution of prostate tissue elements seem to be common during aging in different species of mammals, including the gerbil. These events are probably related to a decline in androgen levels and, due to these hormonal alterations, there is an increase in estrogen levels, which can contribute to the evolution of prostate pathological changes, such as benign hyperplasias and carcinomas (Banerjee et al., 2001).

Many studies have related that, although several rodent models exist for the study of human prostate pathologies, until this moment, none of them have been completely effective in extrapolating data for humans. In several rodents, the occurrence of prostatic lesions is more evident in the ventral prostate. However, since the frequency of prostatic cancer in those animals is very low, there is some speculation about the relevance of these rodent models for human studies (Abate-Shen and Shen, 2000). Recently, this doubt was clarified by Berquin et al. (2005). Their analysis indicated that the gene expression pattern in the dorsolateral lobe of the mouse was similar to the one found on the human prostate peripheral zone, where the majority of human prostate cancers originates. This evidence supports the hypothesis that those prostate compartments are functionally equivalent and therefore comparative studies between human and rodent species are relevant. The features of the gerbil dorsolateral lobe had not been explored yet. However, it is known that this lobe is very prominent in the prostate of this animal (Sabrina Rochel, personal communication).

Further study is required in order to evaluate the peculiar features of each lobe component of the gerbil prostate, as well as their potential in developing spontaneous lesions, since the animal's tissue components alter morphologically and quantitatively with aging in response to androgen decline.

\section{ACKNOWLEDGMENTS}

The authors thank Mr. Luiz Roberto Falleiros, Jr., and Ms. Rosana S. Sousa for technical assistance, as well as all other researchers at the Microscopy and Microanalysis Laboratory. Acknowledgement is also due to Dr. Peter James Harris and Ms. Lara Silvia Corradi for Englishlanguage revision of this article. This article is part of the thesis presented by S.G.P.D.C. to the Institute of Biology, UNICAMP, in partial fulfillment of the requirement for a $\mathrm{PhD}$ degree.

\section{LITERATURE CITED}

Abate-Shen C, Shen MM. 2000. Molecular genetics of prostate cancer. Genes Dev 14:2410-2434.

Alho H, Koistinaho J, Laaksonen HM, Hervonen A. 1989. Effect of lifelong selenium and vitamin E deficiency or supplementation on pigment accumulation in rat peripheral tissues. Adv Exp Med Biol 266:143-155.

Banerjee PP, Banerjee S, Brown TR. 2000. Castration-induced apoptotic cell death in the Brown Norway rat prostate decreases as a function of age. Endocrinology 141:821-832.

Banerjee PP, Banerjee S, Brown TR. 2001. Increased androgen receptor expression correlates with development of age-dependent, lobespecific spontaneous hyperplasia of the Brown Norway rat prostate. Endocrinology 142:4066-4075.

Berquin IM, Min Y, Wu R, Wu H, Chen YQ. 2005. Expression signature of the mouse prostate. J Biol Chem 280:36442-36451.

Bonkhoff H, Remberger K. 1998. Morphogenetic concepts of normal and abnormal growth in the human prostate. Virch Arch 433:195202.

Bostwick DG, Pacelli A, Lopez-Beltran A. 1996. Molecular biology of prostatic intraepithelial neoplasia. Prostate 29:117-134.

Bostwick DG, Ramnani D, Qian J. 2000. Prostatic intraepithelial neoplasia: animal models 2000. Prostate 43:286-294.

Carvalho HF, Taboga SR, Vilamaior PSL. 1997. Collagen type VI is a component of the extracellular matrix microfibril network of the prostatic stroma. Tissue Cell 29:163-170.

Ceccarelli C, Trerè D, Santini D, Taffurelli M, Chieco P, Derenzini M. 2000. AgNORs in breast tumors. Micron 31:143-149.

Corradi LS, Goes RM, Carvalho, HF, Taboga SR. 2004. Inhibition of 5-alpha-reductase activity induces stromal remodeling and smooth muscle de-differentiation in adult gerbil ventral prostate. Differentiation 72:198-208.

Cotta-Pereira G, Rodrigo FG, David-Ferreira JF. 1976. The use of tannic acid-glutaraldehyde in the study of elastic related fibers. Stain Technol 51:7-11.

Cunha GR, Donjacour AA, Sugimura Y. 1986. Stromal-epitelial interactions and heterogeneity of proliferative activity within the prostate. Biochem Cell Biol 64:608-614.

Garraway LA, Lin D, Signoretti S, Waltregny D, Dilks J, Bhattacharya N, Loda M. 2003. Intermediate basal cells of the prostate: in vitro and in vivo characterization. Prostate 55:206-218.

Gross SA, Didio LJA. 1987. Comparative morphology of the prostate in adult male and female of Praomys (mastomys) natalensis studies with electron microscopy. J Submicrosc Cytol 19:77-84.

Hayward SW, Baskin LS, Haughney PC, Foster BA, Cunha AR, Dahiya R, Prins GS, Cunha GR. 1996. Stromal development in the ventral prostate, anterior prostate and seminal vesicle of the rat. Acta Anat 155:94-103.

Horsfall DJ, Mayne K, Ricciardelli C, Rao M, Skinner JM, Henderson DW, Marshall VR, Tilley WD. 1994. Age-related changes in guinea pig prostatic stroma. Lab Invest 70:753-763.

Huss WJ, Maddison LA, Grenberger NM. 2001. Autochthonous mouse models for prostate cancer: past, present and future. Cancer Biol 11:245-259.

Karalyan ZA, Djaghatspanyan NJ, Gasparyan MH, Hakobyan LA, Abroyan LO, Magakyan YH, Ter-Pogossyan ZR, Kamalyan LA, Karalova EM. 2004. Morphometry of the nuclear and nucleolar structures in a CaCo-2 cell line. Cell Biol Int 28:249-253. 
Kimura K, Bowen C, Spiegel S, Gelmann EP. 1999. Tumor necrosis factor $\alpha$ sensitizes prostate cancer cells to $\gamma$-irradiation-induced apoptosis. Cancer Res 59:1606-1614.

Leav I, Schelling KH, Adams JY, Merck FB, Alroy J. 2001. Role of canine basal cells in postnatal prostatic development, induction of hyperplasia, and sex-hormone-stimulated growth, and ductal origin of carcinoma. Prostate 48:210-224.

Marker PC, Donjacour AA, Dahiya R, Cunha GR. 2003. Hormonal, cellular, and molecular control prostatic development. Dev Biol 253:165-174.

McNeal JE. 1983. The prostate gland: morphology and pathobiology. Monogr Urol 4:3-37.

Öfner D. 2000. In situ standardized AgNOR analysis: a simplified method for routine use to determine prognosis and chemotherapy efficiency in colorectal adenocarcinoma. Micron 31:161-164.

Roy-Burman P, Wu H, Powell WC, Hagenkord J, Cohen MB. 2004 Genetically defined mouse models that mimic natural aspects of human prostate cancer development. Endocr Relat Cancer 11:225-254.

Sensibar JA, Pruden SJ, Kasjanski RZ, Rademaker A, Lee C, Grayhack JT, Koslowski JM. 1999. Differential growth rates in stromal cultures of human prostate derived from patients of varying ages. Prostate 38:110-117.

Shirai T, Tahashi S, Cui L, Futakuchi M, Kato K, Tamano S, Imaida K. 2000. Experimental prostate carcinogenesis - rodent models. Mutat Res 462:219-226.

Sprando RL, Collins TFX, Black TN, Olejnik N, Rorie JI, West LJ, Bowers JD, Sass N, Robl M. 1999. Light microscopic observations on the reproductive tract of the male sand rat, Psammomys obesus. Tissue Cell 31:99-115.

Sugimura Y, Cunha GR, Donjacour AA. 1986. Morphogenesis of ductal networks in the mouse prostate. Biol Reprod 34:961-971.
Suwa T, Nyska A, Peckham JC, Hailey JR, Mahler JF, Haseman JK, Maronpot RR. 2001. A retrospective analysis of background lesions and tissue accountability for male accessory sex organs in Fisher344 rats. Toxicol Pathol 29:467-478.

Swinnen JV, Van Veldhoven PP, Esquenet M, Heyns W, Verhoeven G. 1996. Androgens markedly stimulate the accumulation of neutral lipids in the human prostatic adenocarcinoma cell line LNCaP. Endocrinology 137:4468-4474.

Taboga SR, Santos AB, Gonzatti AGR, Vidal BC, Mello MLS. 2003. Nuclear phenotypes and morphometry of human secretory prostate cells: a comparative study of benign and malignant lesions in Brazilian patients. Caryologia 56:313-320.

Taplin ME, Ho S-M. 2001. The endocrinology of prostate cancer. J Clin Endocrinol Metab 86:3467-3477.

Thomson AA. 2001. Role of androgen and fibroblast growth factors in prostatic development. Reproduction 121:187-195.

Tuxhorn JA, Ayala GE, Rowley DR. 2001. Reative stroma in prostate cancer progression. J Urol 166:2472-2483.

Wang Y, Sudilovsky D, Zhang B, Haughney PC, Rosen MS, Wu DS, Cunha TJ, Dahiya R, Cunha GR, Hayward SW. 2001. A human prostatic epithelial model of hormonal carcinogenesis. Cancer Res 61:6064-6072.

Weibel ER. 1978. Principles and methods for the morphometric study of the lung and other organs. Lab Invest 12:131-155.

Williams WM. 1974. The anatomy of the Mongolian gerbil. West Brookfield, MA: Tumblebrook Far.

Zhang YH, Kanamaru H, Oyama N, Miwa Y, Suzuki Y, Akino H, Nokiki S, Okada K. 2000. Prognostic value of nuclear morphometry on needle biopsy from patients with prostate cancer: is volumeweighted mean nuclear volume superior to other morphometric parameters. Urology 55:377-381. 